\title{
Recurrent Submandibular Gland Mucoepidermoid Carcinoma
}

National Cancer Institute

\section{Source}

National Cancer Institute. Recurrent Submandibular Gland Mucoepidermoid Carcinoma. NCl Thesaurus. Code C153807.

The reemergence of submandibular gland mucoepidermoid carcinoma after a period of remission. 